\title{
Nasal Mucosa Necrosis Against Alkaline Battery Foreign Body
}

\section{Caner Sahin*}

Sakarya Akyazi State Hospital, ENT Clinic, Sakarya, Turkey

\begin{abstract}
Foreign body in nose is one of the most Ear nose Throat emergencies. Round alkaline batteries are one of the most dangerious foreign body in the literature. We present a 5 years old boy with nasal mucosa necrosis against alkaline battery foreign body in the lights of literature.
\end{abstract}

Keywords: Foreign body; Alkaline battery; Nose

\section{Introduction}

Foreign body in nose is one of the most Ear nose Throat emergencies. Children may easily put foreign bodies into their noses. Paper, beans, beads and many foreign bodies can be seen in nose. Foreign bodies that cannot be noticed can make one side of nose odor, discharge and long term rhinolith formation may occur because of the foreign body. Button batteries are increasingly used in devices such as toys, watches, electronic games and watches. The incidence of battery ingestions reported to United States centers from 1985 to 2009 was between 6.3 and 15.1 cases per million population. Thirteen deaths related to tissue damage in the esophagus or airway, and 73 major outcomes were described [1].

The clinic of the battery foreign body depends on location of the battery, duration, chemical composition of battery. The alkaline battery foreign body may be fatal [2]. Nasal mucosa necrosis, middle turbinate necrosis and septum perforation may occur. Serious complications may occur in cases with early diagnosis and early removal cannot be done.

We present a 5 years old boy with nasal mucosa necrosis against alkaline battery foreign body in our case report.

\section{Case Report}

5 years old male boy consulted to ENT policlinics. His family is complaint of foreign body in nose. Mother of the boy said he put gameboys battery in his right nose. They tried to take it out but it goes further in nose. Right nasal mucosa edema was present in anterior rhinoscopy. The shining of battery between middle concha and septum was seen in endoscopic examination. The patient was prepared for general anestesia. The patient was ready fort he surgery after the deposition of the foreign body to the nose. The alkaline battery was seen between middle concha and septum with 0 degree ridid endoscope. The foreign body is removed using curette. Bleeding and nechrosis was seen in septum, middle concha and inferior concha (Figure 1). The negative pole of the alkaline battery was toward middle meatus The round battery can be seen in figure (Figure 2). Septal perforation is not present. There was no other pathology toward nasopharynx. Gauze with antibiotics was inserted to nasal mucosa. Graphical inspections showed no pathology in lower gastrointestinal tractus and inferior and superior abdomen. The nasal tampone was removed after 48 hours. The patient is followed for 1 mounth with no complication.

\section{Discussion}

The nose is an easily accesible anatomic region. Childs can easily reach this region. Foreign body in nose can be seen in children, mental retardation and psychiatric patients. Many objects can placed to nose as foreign body. Many of them can be replaced out without any early/ late complication. If the foreign body is left there may be discharge or rhinolith formation but can be cured anyway [3].

There is an difference if the foreign body is battery. Especially round alkaline batteries are one of the most dangerious foreign body in the literature [4]. Mucosal perforation, septum perforation, esophagus and gastrointestinal perforation may occur if proper diagnosis and early management cannot be done. The risk of complication is increased as the contact time of battery is increased. Nasal mucosa damage is started 8 hour after insertion of the battery [5]. We take our foreign body 10 hours after diagnosis. There was no septal perforation. The contact surface of the battery is also important. The risk of damage is increased if the negative pole of the battery is in contact with nasal septum. After the contact of the battery liquefaction necrosis occurs in time. Also the thickness of the battery is important. As the thickness is increased pressure and possible chemical interaction is increased.

There are 5 types of batteries based on chemical composition: manganese, silver, mercury, lithium, and zinc. The composition of the batteries are mostly alkaline today [6].

Four mechanisms of injury have been described in the literature: 1) leakage of the battery contents with direct corrosive damage, 2) direct electrical current effects on the mucosa and resultant mucosal burns, 3 )

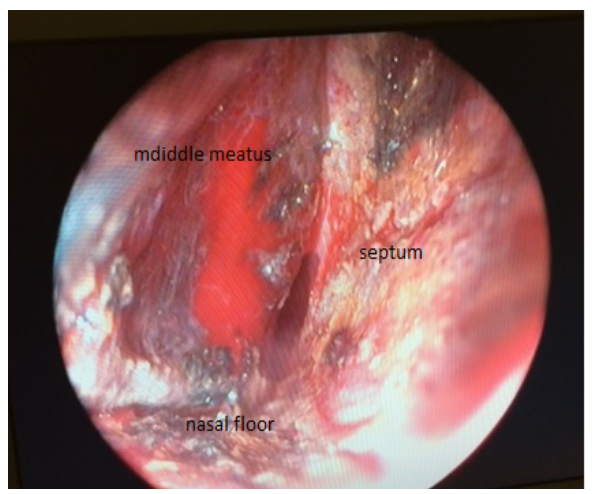

Figure 1: Bleeding, necrosis and edema of middle meatus, septum can be seen in the figure after removal of the battery.

*Corresponding author: Caner Sahin, Sakarya Akyazi State Hospital, ENT Clinic Sakarya, Turkey, Fax: +90-264-4187835; E-mail: drcaner2001@gmail.com

Received October 01, 2014; Accepted October 29, 2014; Published October 31 2014

Citation: Sahin C (2014) Nasal Mucosa Necrosis Against Alkaline Battery Foreign Body. J Clin Case Rep 4: 444. doi:10.4172/2165-7920.1000444

Copyright: (c) 2014 Sahin C. This is an open-access article distributed under the terms of the Creative Commons Attribution License, which permits unrestricted use, distribution, and reproduction in any medium, provided the original author and source are credited. 


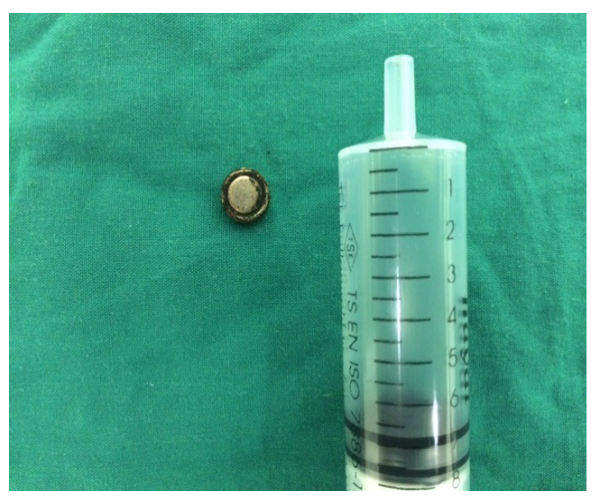

Figure 2: The negative pole of the battery can be seen.

pressure necrosis resulting from prolonged local pressure and 4) local toxic effect due to absorption of substances [7]. The leaked alkaline electrolyte solution can penetrate deep into tissues. This may cause liquefying necrosis of tissues. Dissolution of protein and collagen, saponification of lipids, dehydration of tissue cells, and consequential extensive tissue damage [8]. The pathology is different from other foreign bodies because of this pathogenesis.

\section{Conclusion}

Foreign body in nose are common complaint in ENT practice. Round alkaline battery in nose is an ENT emergency because of its possible complications. Early diagnosis and treatment as soon as possible is crucial because of this reasons.

\section{References}

1. Litovitz $T$, Whitaker $N$, Clark $L$ (2010) Preventing battery ingestions: an analysis of 8648 cases. Pediatrics 125: 1178-1183.

2. Loh WS, Leong JL, Tan HK (2003) Hazardous foreign bodies: complications and management of button batteries in nose. Ann Otol Rhinol Laryngol 112 379-383.

3. Sharpe SJ, Rochette LM, Smith GA (2012) Pediatric battery-related emergency department visits in the United States, 1990-2009. Pediatrics 129: 1111-1117.

4. Guidera AK, Stegehuis HR (2010) Button batteries: the worst case scenario in nasal foreign bodies. N Z Med J 123: 68-73.

5. McRae D, Premachandra DJ, Gatland DJ (1989) Button batteries in the ear nose and cervical esophagus: a destructive foreign body. J Otolaryngol 18 : 317-319.

6. Thompson N, Lowe-Ponsford F, Mant TG, Volans GN (1990) Button battery ingestion: a review. Adverse Drug React Acute Poisoning Rev 9: 157-180.

7. Soerdjbalie-Maikoe V, van Rijn RR (2010) A case of fatal coin battery ingestion in a 2-year-old child. Forensic Sci Int 198: e19-22.

8. Thabet MH, Basha WM, Askar S (2013) Button battery foreign bodies in children: hazards, management, and recommendations. Biomed Res Int 2013 846091. 